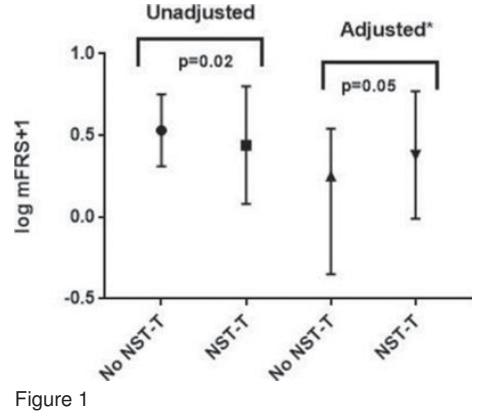

Abnormalities With Cardiovascular Mortality The Chicago Western Electric Study. JAMA. 1999;281(6):530-536.

[4] Urowitz MB, Ibañez D, Gladman DD,et al. Modified Framingham Risk Factor Score for Systemic Lupus Erythematosus. J Rheumatol. 2016 May;43(5):8759.

Disclosure of Interest: None declared

DOI: 10.1136/annrheumdis-2017-eular.4655

\section{THU0270 HOMOCYSTEINE, ANTIPHOSPHOLIPID ANTIBODIES AND RISK OF VASCULAR EVENTS IN PATIENTS WITH SYSTEMIC LUPUS ERYTHEMATOSUS}

G. Stojan, W. Fu, M. Petri. Rheumatology, Johns Hopkins University, Baltimore, United States

Background: SLE patients have higher plasma total homocysteine concentrations compared to healthy controls. Hyperhomocysteinemia in SLE is a potentially modifiable, independent risk factor for stroke and thrombotic events, hypertension, and coronary artery calcification.

Objectives: We investigated the association of homocysteine levels with the presence of antiphospholipid antibodies as well as the potentially additive thrombotic risk in patients with antiphospholipid antibodies who have hyperhomocysteinemia. Methods: To analyze the association between hyperhomocysteinemia and the presence of antiphospholipid antibodies in SLE, 844 patients with homocysteine measurements were included in the analysis. 237 patients had at least one measurement over $15 \mathrm{umol} / \mathrm{L}$. Patients were followed quarterly after cohort entry. The association of hyperhomocysteinemia with antiphospholipid antibodies is detailed in Table 1.

Table 1. Homocysteine and antiphospholipid antibody positivity

\begin{tabular}{lcccccc}
\hline & $\begin{array}{c}\text { Homocysteine } \\
\text { (umol/L) }\end{array}$ & $\begin{array}{c}\text { Odd ratios } \\
(95 \% \mathrm{Cl})\end{array}$ & \begin{tabular}{c} 
P value \\
\cline { 2 - 8 }
\end{tabular} & $\begin{array}{c}\text { Adj. Odd ratios } \\
(95 \% \mathrm{Cl})\end{array}$ & $\begin{array}{c}\text { Adj. } \\
\text { P value }\end{array}$ \\
\hline Anti-cardiolipin & $43.24)$ & 57.62 & $0.56(0.37,0.84)$ & 0.0049 & $0.54(0.36,0.81)$ & 0.0033 \\
Anti-B2 Glycoprotein & 16.98 & 29.69 & $0.48(0.28,0.82)$ & 0.0076 & $0.46(0.27,0.8)$ & 0.0054 \\
Lupus anticoagulant & 19.82 & 29.29 & $0.6(0.36,0.98)$ & 0.0404 & $0.54(0.33,0.91)$ & 0.0190 \\
\hline
\end{tabular}

To analyze the prevalence of vascular events among SLE patients with antiphospholipid antibodies based on homocysteine levels, 571 patients with positive antiphospholipid antibodies and at least one homocysteine measurement were included in the analysis. There were 166 patients with at least one homocysteine measurement over $15 \mathrm{umol} / \mathrm{L}$.

The lupus anticoagulant was assessed by dRVVT with mixing studies and confirmatory tests. Anticardiolipin and anti-beta2 glycoprotein 1 were measured by ELISA (INOVA). Vascular events were defined as stroke, myocardial infarction, digital gangrene, and deep vein thrombosis.

Results:

Table 2. Prevalence of vascular events among SLE patients with antiphospholipid antibodies based on homocysteine levels

\begin{tabular}{lccc}
\hline & Abnormal Homocysteine $>15$ umol/L & Normal Homocysteine & P value \\
& $\mathrm{N}(\%)$ & $\mathrm{N}(\%)$ & \\
\hline Superficial Thrombosis & $4(2.41)$ & $12(2.96)$ & 0.7176 \\
Deep vein thrombosis & $37(22.29)$ & $58(14.36)$ & 0.0257 \\
Stroke & $17(10.24)$ & $30(7.41)$ & 0.3139 \\
Myocardial infarction & $13(7.83)$ & $11(2.72)$ & 0.0099 \\
Digital Gangrene & $4(2.41)$ & $8(1.98)$ & 0.7523 \\
\hline
\end{tabular}

Conclusions: SLE patients with elevated homocysteine were less likely $(p<0.05)$ to have any of the antiphospholipid antibodies. Among patients with SLE who have antiphospholipid antibodies, elevated homocysteine is associated with a significantly higher prevalence of myocardial infarction and deep vein thrombosis $(\mathrm{p}<0.05)$.

Disclosure of Interest: None declared

DOI: 10.1136/annrheumdis-2017-eular.6705

\section{THU0271 THE PERFORMANCE OF DIFFERENT CLASSIFICATION CRITERIA IN PATIENTS WITH PRIMARY SJOGREN'S SYNDROME AND ANALYSIS OF THEIR CONTRIBUTION FOR DEFINITIVE DIAGNOSIS, WHEN EITHER CRITERIA USED ALONE OR IN COMBINATION}

Z. Kosuva Ozturk ${ }^{1}$, G. Kenar ${ }^{2}$, H. Yarkan Tugsal ${ }^{2}$, B. Zengin ${ }^{2}$, G. Can ${ }^{2}$, F. Onen ${ }^{2}$, M. Birlik ${ }^{2} .{ }^{1}$ Internal Medicine; ${ }^{2}$ Rheumatology, Dokuz Eylul University School of Medicine, Izmir, Turkey

Background: Many classification criteria sets have been proposed for primary Sjögren's Syndrome (pSS),consisting of variable features of the disease.Despite increasing number of criteria sets, expert opinion is still keeping its importance for the diagnosis of pSS.

Objectives: We aimed to compare the performance of 3 classification criteria sets for pSS, to determine the agreement between each other and expert opinion and to investigate diagnostic contribution with any combined use of these criteria.For those assessments, American-European Consensus Criteria (AECG), American Collage of Rheum (ACR)/Sjögren Int. Clinical Alliance (SICCA) criteria and L.S. Martin et al. criteria named Mathematical model (M.model) had chosen. The M.model is a criteria set known to be noninvasive and proposed as highly specific. Methods: 86 patients (F: $96 \%$, mean age: $51.7 \pm 11.8$ ) following up in our clinic with the diagnosis of pSS were enrolled to the study.Expert opinion had been taken as gold standard for pSS diagnosis. Patients were questioned for eye/mouth dryness. Antinuclear antibody (ANA), complement (C3, C4), anti-Ro and anti-La, serum protein electrophoresis, rheumatoid factor (RF), break-up time (BUT) and Schirmer, minor salivary gland biopsy results were analysed cautiously. The aforementioned criteria sets, were implemented to assess the classification. The percentage of exact agreement and Kappa test was calculated.

Results: Number of patients classified as pSS according to ACR/SICCA, AECG and M.model criteria were $75(87 \%), 63(73 \%)$ and $58(67 \%)$ respectively. 9 patients (10\%) did not fulfill any of these 3 criteria but they were diagnosed as pSS according to expert opinion (Image 1). The Kappa test was moderate between the ACR/SICCA and AECG criteria and slightly low between the M.model with the $A E C G$ and ACR/SICCA criteria (Table 1). According to our proposed combination model, number of patients classified as pSS, either AECG or M.model was 74(86\%); either AECG or ACR/SICCA model was 76(88\%); either ACR/SICCA or M.model was $77(89.5 \%)$ (Table 2). In the triple combination of our model, if all 3 criteria used concomitantly, only $46(51 \%)$ of patients fulfill the criteria simultaneously; however if any of 3 criteria sets used 77 (89.5\%) patients fulfill as pSS.

\begin{tabular}{|c|c|c|c|c|}
\hline & AECG & ACR/SICCA & \multicolumn{2}{|c|}{ M.MODEL } \\
\hline AECG & & $\% 83 \mathrm{~K}: 0.50$ & \multirow{2}{*}{\multicolumn{2}{|c|}{$\% 68 \mathrm{~K}: 0.25$}} \\
\hline ACR/SICCA & $\% 83 \mathrm{~K}: 0.50$ & & & \\
\hline M.MODEL & $\% 68 \mathrm{~K}: 0.25$ & $\% 75 \mathrm{~K}: 0.34$ & \multicolumn{2}{|c|}{$\% 75 \mathrm{~K}: 0.34$} \\
\hline \multicolumn{5}{|l|}{ Table 2} \\
\hline & & Classsification criteria & (n) & $(\%)$ \\
\hline \multirow{3}{*}{\multicolumn{2}{|c|}{ According to 1 criteria }} & ACR/SICCA & 75 & 87,2 \\
\hline & & AECG & 63 & 73,2 \\
\hline & & M. model & 58 & 67,4 \\
\hline \multirow{3}{*}{\multicolumn{2}{|c|}{ According to either of 2 criteria }} & ACR/SICCA or M.model & 77 & 89,5 \\
\hline & & AECG or ACR/SICCA & 76 & 88,3 \\
\hline & & AECG or M. model & 74 & 86 \\
\hline \multirow{2}{*}{\multicolumn{2}{|c|}{ According to either of 3 criteria }} & AECG or ACR/SICCA or M.model & 77 & 89,5 \\
\hline & & AECG + ACR/SICCA + M.model & 46 & 51.6 \\
\hline
\end{tabular}

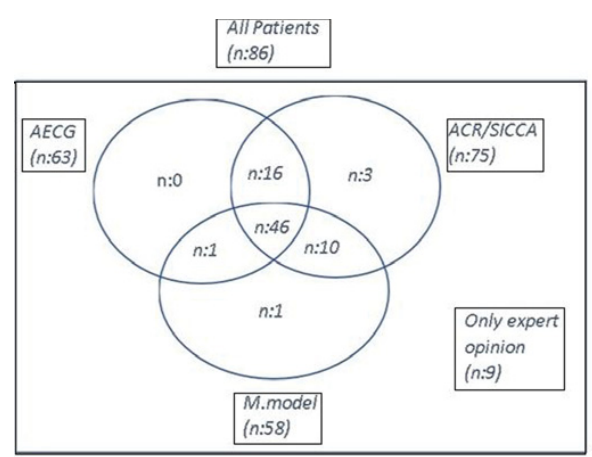

Conclusions: In this study, ACR/SICCA classification criteria for pSS was found the most compatible criteria set with expert opinion, when it used alone. The combination of either ACR/SICCA or M.model was found to be the most sensitive binary combination for classification with similar results as triple combination. This study showed that a small group of patients could not be classified as pSS even if the criteria sets were used with concomitant combinations. It was determined that experienced specialists were largely need to recognize and distinguish these patients.

Disclosure of Interest: None declared

DOI: 10.1136/annrheumdis-2017-eular.6074 